\title{
Status of Rehabilitation After Ischemic Stroke: A Korean Nationwide Study
}

\author{
Won-Sep Kim, MD ${ }^{1}$, Hee-Joon Bae, MD², Hyun-Haeng Lee, MD ${ }^{1}$, Hyung Ik Shin, MD \\ ${ }^{1}$ Department of Rehabilitation Medicine, Seoul National University College of Medicine, Seoul; \\ ${ }^{2}$ Department of Neurology, Seoul National University Bundang Hospital, Seongnam, Korea
}

\begin{abstract}
Objective To investigate the post-stroke rehabilitation status according to stroke severity using the database of the Korean Health Insurance Review and Assessment Service.

Methods The data of patients admitted to the neurology departments of 12 hospitals within 7 days of onset of ischemic stroke were collected. A total of 2,895 patients hospitalized between November 2010 and December 2011 were included. The patients were classified into three groups according to their initial National Institutes of Health Stroke Scale (NIHSS) scores (mild, $\leq 5$; moderate, $>5$ and $\leq 13$; and severe, $>13$ ). Length of hospital stay (LoS) with rehabilitation, NIHSS score after acute care, and scores on modified Rankin Scale (mRS) were examined at 1 year post-stroke according to stroke severity and ongoing rehabilitation.

Results The total LoS for ongoing rehabilitation significantly increased with stroke severity (mild, 91.66 \pm 149.70 ; moderate, 197.26 \pm 241.93 ; severe, $263.50 \pm 275.75$ days; $\mathrm{p}<0.01$ ). However, the proportion of LoS with ongoing rehabilitation to the total LoS tended to decline with increasing stroke severity (mild, $77.93 \pm 29.50, \mathrm{p}<0.01$; moderate, $71.83 \pm 32.13$; severe, $62.29 \pm 37.19$ ). The home discharge rate of the group that underwent continuous inpatient rehabilitation was significantly higher in patients with moderate and severe stroke, respectively ( $14.2 \%$ vs. $0.0 \%, \mathrm{p}<0.001 ; 7.4 \%$ vs. $0.0 \%, \mathrm{p}=0.032$ ).

Conclusion This study showed that intermittent rehabilitation was often provided after acute care, whereas ongoing rehabilitation positively affected rate of home discharge in patients with moderate and severe stroke in Korea. These results represent evidence for improving the healthcare system to promote adequate rehabilitation in the future.
\end{abstract}

Keywords Stroke rehabilitation, Patient acuity, Cerebrovascular disorders, Database

Received July 19, 2017; Accepted September 26, 2017

Corresponding author: Hyung Ik Shin

Department of Rehabilitation Medicine, Seoul National University Hospital, 101 Daehak-ro, Jongno-gu, Seoul 03080, Korea. Tel: +82-2-2072-3218, Fax: +82-2-743-7473, E-mail: hyungik1@snu.ac.kr

ORCID: Won-Sep Kim (http://orcid.org/0000-0001-6097-3021); Hee-Joon Bae (http://orcid.org/0000-0003-0051-1997); Hyun-Haeng Lee (http://orcid. org/0000-0001-6666-6284); Hyung Ik Shin (http://orcid.org/0000-0001-8805-3104).

(c) This is an open-access article distributed under the terms of the Creative Commons Attribution Non-Commercial License (http://creativecommons.org/ licenses/by-nc/4.0) which permits unrestricted noncommercial use, distribution, and reproduction in any medium, provided the original work is properly cited. Copyright $\odot 2018$ by Korean Academy of Rehabilitation Medicine 


\section{INTRODUCTION}

The best practice for post-stroke recovery is extensive rehabilitation to reduce the initial impact caused by the disease, prevent complications, and maximize functional improvement [1-3]. The efficacy of rehabilitation has been extensively documented in previous studies, and a meta-analysis (including 36 randomized controlled studies and 79 controlled studies) of its effectiveness revealed that stroke patients who undergo systematic rehabilitation show better functional improvement than the control group [4,5]. Further, stroke patients who undergo organized rehabilitation exhibited lower mortality (odds ratio $[\mathrm{OR}]=0.86$; 95\% confidence interval $[\mathrm{CI}], 0.71-0.94$ ), a lower rate of discharge to a long-term care facility ( $\mathrm{OR}=0.80 ; 95 \% \mathrm{CI}, 0.71-0.91$ ), and relatively mild disabilities after stroke (OR=0.78; 95\% CI, 0.68-0.89). In other words, systematic rehabilitation contributes to a better prognosis [6], and appropriate rehabilitation is essential for successful recovery of stroke patients.

According to a Korean study, only $22.9 \%$ of first-time stroke patients undergo rehabilitation after acute care, and only $12.9 \%$ approach rehabilitation medicine for comprehensive management [7]. However, the study lacked sufficient evidence to support the role of appropriate rehabilitation according to stroke severity. Further, the study data were collected from only three university hospitals, rendering it difficult to generalize the findings to the overall post-stroke rehabilitation system in Korea. Recently, a few studies investigated the length of hospital stay (LoS) in relation to stroke severity, and showed that the LoS of stroke patients in Korea was longer than in the United States or Japan $[8,9]$. In Korea, LoS increases with stroke severity, and is unnecessarily long even in cases of mild stroke, which needs no further inpatient rehabilitation, suggesting the possibility of inefficiency in the current healthcare system [8]. However, this study also failed to elucidate on possible differences in the provision of rehabilitation in relation to the severity of stroke.

Unfortunately, improving the current rehabilitation system is a challenge due to the lack of nationwide data in Korea related to continuous rehabilitation after acute care in stroke patients and the differences in the duration of inpatient rehabilitation in relation to stroke severity.

Therefore, in this study, we investigated the status of post-stroke rehabilitation according to stroke severity based on the Korean Health Insurance Review and Assessment Service (HIRA) database.

\section{MATERIALS AND METHODS}

\section{Data collection}

The cohort dataset from the Multicenter Prospective Observational Study about Recurrence and its Determinants after Acute Ischemic Stroke (MOSAIC) was used in the present study. This data were obtained from neurologists at 12 university hospitals in Korea. Specifically, the data were retrieved from patients who suffered an ischemic stroke (not hemorrhagic stroke or transient ischemic attack) between January 2009 and November 2013 and admitted to a hospital within 7 days of symptom onset. A total of 15,742 patients consented to participate in the study, and 3,794 patients who satisfied the following inclusion criteria were recruited: (1) hospitalization between November 2010 and December 2011, (2) no prior history of stroke (initial modified Rankin Scale [mRS] score $=0$ ), and (3) age 20 years or older.

The exclusion criteria were: (1) missing requisite clinical information; (2) patients who were dead at the time of discharge from an acute care center $(\mathrm{mRS}=6)$; (3) patients who had a recurrent stroke or cerebrovascular accident within a year from the initial stroke onset; and (4) patients who were dead at the 1-year follow-up after stroke (mRS=6). The final analysis included 2,895 patients (Fig. 1). The following variables were extracted from the dataset: age, sex, date of admission to an acute care center, the National Institutes of Health Stroke Scale (NIHSS) score at the time of admission to an acute care center, date of discharge from an acute care center, and NIHSS score at the time of discharge from an acute care center. Patient information regarding hospital stay after discharge from an acute care center was investigated using the HIRA database. The investigator was connected to the database after ensuring secure access. We investigated the LoS at each hospital (from an acute care center until patients' discharge to home). We determined whether an insurance claim was made for professional rehabilitation therapy-e.g., rehabilitative development therapy for disorder of central nervous system, rehabilitative functional training (mattress or mobilization training or gait training), special occupational therapy, activities of daily living training, functional electrical stimulation therapy- 
Table 1. Patients' demographics

\begin{tabular}{lcccc}
\hline & \multicolumn{3}{c}{ Severity of stroke $^{\text {a) }}$} & \multirow{2}{*}{ Total } \\
\cline { 2 - 4 } & Mild & Moderate & Severe & \\
\hline Number of patients & $2,125(73.4)$ & $534(18.4)$ & $236(8.2)$ & 2,895 \\
Age (yr) & $64.91 \pm 12.22^{* *}$ & $66.61 \pm 12.71$ & $67.89 \pm 11.92$ & $65.46 \pm 12.33$ \\
\hline Sex & & & & \\
Male & 1,351 & 314 & 129 & 1,794 \\
Female & 774 & 220 & 107 & 1,101 \\
\hline LoS in the acute care center (day) & $9.75 \pm 10.08^{* *}$ & $12.21 \pm 7.40^{* *}$ & $18.52 \pm 27.41^{* *}$ & $10.92 \pm 12.31$ \\
& $8(6-11)$ & $10(7-15)$ & $14(8-22)$ & $9(6-12)$ \\
\hline Total LoS after stroke (day) & $71.99 \pm 150.54^{* *}$ & $235.34 \pm 293.28^{* *}$ & $385.93 \pm 356.76^{* *}$ & $127.71 \pm 229.48$ \\
& $14(7-62)$ & $92(19-334)$ & $273(63-663)$ & $30(8-115)$ \\
\hline Total number of hospitals admitted & $2.50 \pm 2.12^{* *}$ & $4.09 \pm 2.83^{* *}$ & $4.79 \pm 2.65^{* *}$ & $2.98 \pm 2.45$ \\
& $1(1-4)$ & $4(1-6)$ & $4.5(3-6)$ & $2(1-4)$ \\
\hline
\end{tabular}

Values are presented as number (\%) or mean \pm standard deviation or median (interquartile range, 25th-75th percentile).

LoS, length of hospital stay.

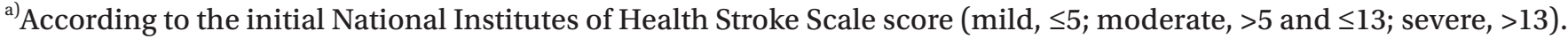
${ }^{*} \mathrm{p}<0.05,{ }^{* *} \mathrm{p}<0.01$.

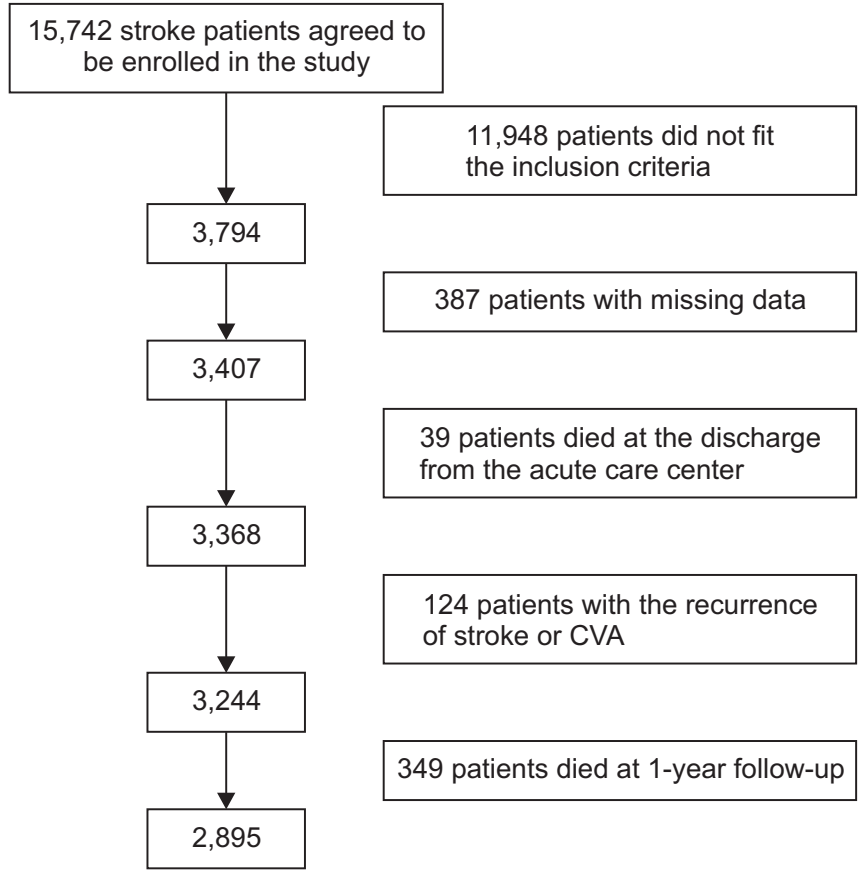

Fig. 1. Flow chart outlining subject recruitment. CVA, cerebrovascular accident.

during the hospital stay. When an insurance claim for professional rehabilitation therapy was submitted, we considered the patient to have undergone inpatient rehabilitation services. This study was approved by the Institutional Review Board of the Seoul National University
Bundang Hospital in Korea (No. B-1508/310-114).

\section{Statistical analysis}

Subgroup analysis was performed by allocating patients into different groups based on stroke severity. Stroke severity was quantified based on the NIHSS score at the time of admission to an acute care center: mild, $\leq 5$; moderate, $>5$ and $\leq 13$; and severe, $>13$ [10]. The normality of the continuous data was verified with the ShapiroWilk test. The Kruskal-Wallis test was used to analyze non-normal data and to compare categorical data across three groups, and the Tukey method was employed for post-hoc analysis. When comparing two groups based on patient rehabilitation, categorical variables (e.g., home discharge rate) were analyzed using Fisher exact test, and continuous variables (e.g., total LoS, total LoS for rehabilitation therapy) were analyzed using the Mann-Whitney U test.

\section{RESULTS}

\section{Demographics}

A total of 2,895 patients were recruited (Fig. 1), including 2,125 mild cases (73.4\%), 534 moderate cases (18.4\%), and 236 with severe stroke (8.2\%) (Table 1). The mean age and standard deviation of the study population was $65.46 \pm 12.33$ years, and the participants in the mild group 
were significantly younger than in the moderate and severe groups $(64.91 \pm 12.22$ years, $\mathrm{p}<0.01)$. LoS at an acute care center tended to rise with increasing stroke severity, and significantly differed across the three groups (mild group, $9.75 \pm 10.08$ days; moderate group, $12.21 \pm 7.40$ days; severe group, $18.52 \pm 27.41$ days; all $\mathrm{p}<0.01)$. Furthermore, post-stroke LoS also significantly differed across the three groups (mild group, $71.99 \pm 150.54$ days; moderate group, $235.34 \pm 293.28$ days; severe group, $385.93 \pm 356.76$ days; $\mathrm{p}<0.01)$.

\section{Rehabilitation after acute care}

Patients in the moderate and severe groups who continued to undergo rehabilitation after acute care were classified under group A, and those who were transferred from an acute care center to a hospital without rehabilitation services were categorized into group B. Patients who were discharged after acute care were included in group C. The home discharge rate in patients included in the moderate severity group A from the second hospital was significantly higher than in patients under group B (14.2\% vs. $0.0 \%, p<0.001)$. Respective $\mathrm{mRS}$ and NIHSS scores in moderate severity group A at the time of discharge from an acute care center were significantly higher than in groups B and C combined (groups that failed to undergo rehabilitation after acute care) $(2.70 \pm 1.73$ vs. $2.31 \pm 1.67$, $\mathrm{p}=0.005 ; 6.45 \pm 3.75$ vs. $5.43 \pm 4.21, \mathrm{p}<0.001$ ) (Table 2 ). Such trends were also evident in the severe group, with significantly higher home discharge rate in the group A from the second hospital compared with group B $(7.4 \%$ vs. $0.0 \%, p=0.032)$. Further, the NIHSS score in the severe group A at the time of discharge from an acute care center was significantly higher than combined scores in the groups B and C ( $12.34 \pm 5.86$ vs. $10.53 \pm 7.09, \mathrm{p}<0.05)$ (Table $3)$.

\section{Comparison of LoS for rehabilitation by stroke severity}

We compared the rehabilitation status in relation to stroke severity (Table 4). The total LoS in a hospital that offered rehabilitation significantly increased with increasing stroke severity (mild, $55.19 \pm 126.49$ days; moderate, 187.02 \pm 253.10 days; severe, $331.07 \pm 339.66$ days; all $\mathrm{p}<0.01)$. The number of patients who received rehabilitation in at least one hospital after discharge from an acute care center also significantly increased with increasing stroke severity $(45.7 \%, 74.3 \%, 84.3 \%$; $<<0.01)$. In other words, $54.3 \%, 25.7 \%$, and $15.7 \%$ of the patients in the mild, moderate, and severe stroke groups, respectively, never received any rehabilitation after acute care. The total LoS for continuous rehabilitation, defined as subsequent inpatient rehabilitation followed by discharge from an acute care center, also significantly increased with the

Table 2. Rehabilitation after acute care in the moderate group

\begin{tabular}{lcccc}
\hline & Group A (n=260) & Group B (n=137) & Group C (n=137) & p-value \\
\hline Home discharge rate from 2nd hospital & $37(14.2)$ & $0(0)$ & NA & $<0.001^{* *}$ \\
Total LoS (day) & $318.00 \pm 314.90$ & $304.06 \pm 281.31$ & $9.82 \pm 5.34$ & 0.530 \\
& $178(65-531)$ & $183(80-432)$ & $8(6-12)$ & $0.046^{*}$ \\
mRS at 1-year follow-up & $2.33 \pm 1.57$ & $2.08 \pm 1.51$ & 0.357 \\
NIHSS on admission to acute care center & $2(1-4)$ & $2(1-3)$ & $<0.001^{* *}$ \\
& $8.57 \pm 2.22$ & $8.41 \pm 2.23$ & $0.005^{* *}$ \\
NIHSS on discharge from acute care center & $8(7-10)$ & $8(6-10)$ & $5.43 \pm 4.21$ & $5(2-8)$ \\
\hline
\end{tabular}

Values are presented as number (\%) or mean \pm standard deviation or median (interquartile range, 25th-75th percentile).

LoS, length of hospital stay; mRS, modified Rankin Scale; NIHSS, National Institutes of Health Stroke Scale; NA, not applicable; Group A, patients underwent rehabilitation therapy continuously following discharge from acute care center; Group B, patients did not undergo rehabilitation therapy following discharge from acute care center; Group C, patients were discharged home after acute care.

${ }^{*} \mathrm{p}<0.05,{ }^{* *} \mathrm{p}<0.01$. 
Table 3. Rehabilitation after acute care in the severe group

\begin{tabular}{lcccc}
\hline & Group A (n=135) & Group B (n=64) & Group C (n=37) & p-value \\
\hline Home discharge rate from 2nd hospital & $10(7.4)$ & $0(0)$ & NA & $0.032^{*}$ \\
Total LoS (day) & $505.16 \pm 355.52$ & $349.73 \pm 304.27$ & $13.86 \pm 11.48$ & $0.006^{* *}$ \\
\hline & $443(172-761)$ & $240(103-521)$ & $9(7-15)$ & \\
mRS at 1-year follow-up & $3.21 \pm 1.51$ & $2.91 \pm 1.79$ & 0.032 \\
NIHSS on admission to acute care center & $3(2-4)$ & $3(1-4)$ & 0.067 \\
& $17.38 \pm 3.22$ & $17.28 \pm 3.32$ & $0.048^{*}$ \\
NIHSS on discharge from acute care center & $17(15-19)$ & $16(15-19)$ & 0.472 \\
\hline
\end{tabular}

Values are presented as number (\%) or mean \pm standard deviation or median (interquartile range, 25th-75th percentile).

LoS, length of hospital stay; mRS, modified Rankin Scale; NIHSS, National Institutes of Health Stroke Scale; NA, not applicable; Group A, patients underwent rehabilitation therapy continuously following discharge from acute care center; Group B, patients did not undergo rehabilitation therapy following discharge from acute care center; Group C, patients were discharged home after acute care.

${ }^{*} \mathrm{p}<0.05,{ }^{* *} \mathrm{p}<0.01$.

severity of stroke (mild, 91.66 \pm 149.70 days; moderate, $197.26 \pm 241.93$ days; severe, $263.50 \pm 275.75$ days; $p<0.01$ ). However, the ratio of LoS for continuous rehabilitation to the total LoS tended to decline with increasing severity. The mild group differed significantly from the other two groups, without any significant difference between the moderate and severe groups (mild, 77.93 \pm 29.50 , $\mathrm{p}<0.01$; moderate, $71.83 \pm 32.13$; severe, $62.29 \pm 37.19$ ).

\section{DISCUSSION}

This study investigated the recent status of post-stroke rehabilitation in Korea. The median LoS with rehabilitation in the mild, moderate, and severe stroke groups was 13 days, 65 days, and 191 days, respectively. No rehabilitation after acute care was provided to $54.3 \%, 25.7 \%$, and $15.7 \%$ of the patients in the three groups, respectively. Even among patients who received intermittent rehabilitation, which is not continuous but includes at least additional inpatient rehabilitation after acute care, accounted for $35.1 \%, 34.5 \%$, and $27.1 \%$, respectively. In addition, the proportion of LoS with continuous rehabilitation in the total LoS tended to decrease with increasing severity. This result suggests that a large proportion of patients do not undergo continuous rehabilitation after acute care and that patients with severe stroke do not receive continuous rehabilitation during the total LoS compared with those diagnosed with mild stroke. This result may be attributed to the lack of rehabilitation of patients who are transferred to a different hospital after acute care regardless of the need or contraindications to continuous rehabilitation due to multiple comorbidities and high incidence of medical complications in patients with severe stroke $[11,12]$. However, this study failed to analyze the effect of such factors on continuous rehabilitation. Continuous rehabilitation improves functional outcomes of patients with moderate stroke and reduces mortality of patients with severe stroke [13-18]. Hence, in order to improve the results, further studies are necessary to explore the factors associated with the decline in continuous rehabilitation with increasing stroke severity.

The proportion of patients discharged from the second hospital was significantly higher in the group A, which continued to undergo rehabilitation after discharge from an acute care center, than in the group B comprising patients who were transferred to a hospital without rehabilitation after acute care, in both moderate and severe groups. Rehabilitation between 4 weeks and 6 months post-stroke may improve functional outcome [17], and therefore, patients who continuously receive rehabilitation starting in an acute care center and extending to subsequent healthcare facilities are more likely to be dis- 
Table 4. Comparison of LoS for rehabilitation by stroke severity

\begin{tabular}{|c|c|c|c|c|}
\hline & \multicolumn{3}{|c|}{ Severity of stroke ${ }^{\text {a) }}$} & \multirow{2}{*}{ Total $(n=2,895)$} \\
\hline & Mild $(n=2,125)$ & Moderate $(n=534)$ & Severe $(n=236)$ & \\
\hline $\begin{array}{l}\text { Total LoS with rehabilitation } \\
\text { therapy }\end{array}$ & $\begin{array}{l}55.19 \pm 126.49^{* *} \\
13(7-43)\end{array}$ & $\begin{array}{l}187.02 \pm 253.10^{* *} \\
65(18-247)\end{array}$ & $\begin{array}{l}331.07 \pm 339.66^{* *} \\
191(47-579)\end{array}$ & $\begin{array}{l}101.99 \pm 200.33 \\
24(8-76)\end{array}$ \\
\hline $\begin{array}{l}\text { Number of patients treated } \\
\text { with at least } 1 \text { rehabilitation } \\
\text { therapy after acute center }\end{array}$ & $972(45.7)^{* *}$ & $397(74.3)^{* *}$ & $199(84.3)^{* *}$ & $1,568(54.2)$ \\
\hline $\begin{array}{l}\text { Number of patients without } \\
\text { any rehabilitation therapy } \\
\text { after acute center }{ }^{\text {b) }}\end{array}$ & $1,153(54.3)$ & $137(25.7)$ & $37(15.7)$ & $1,327(45.8)$ \\
\hline $\begin{array}{l}\text { Number of patients undergo- } \\
\text { ing continuous/intermittent } \\
\text { rehabilitation therapyc) }\end{array}$ & $\begin{array}{c}631 / 341 \\
(64.9 / 35.1)\end{array}$ & $\begin{array}{c}260 / 137 \\
(65.5 / 34.5)\end{array}$ & $\begin{array}{c}135 / 64 \\
(72.9 / 27.1)\end{array}$ & $\begin{array}{l}1,026 / 542 \\
(65.4 / 34.6)\end{array}$ \\
\hline $\begin{array}{l}\text { Los with continuous rehabili- } \\
\text { tation therapy }\end{array}$ & $\begin{array}{l}91.66 \pm 149.70^{* *} \\
42(30-79)\end{array}$ & $\begin{array}{l}197.26 \pm 241.93^{* *} \\
75(41-245)\end{array}$ & $\begin{array}{l}263.50 \pm 275.75^{* *} \\
140(62-382)\end{array}$ & $\begin{array}{c}141.03 \pm 206.84 \\
55(32-139)\end{array}$ \\
\hline $\begin{array}{l}\text { Proportion of LoS with contin- } \\
\text { uous rehabilitation therapy }{ }^{d}\end{array}$ & $\begin{array}{c}77.93 \pm 29.50^{* *} \\
95.83(62.79-100.00)\end{array}$ & $\begin{array}{c}71.83 \pm 32.13 \\
87.79(47.01-100.00)\end{array}$ & $\begin{array}{c}62.29 \pm 37.19 \\
77.99(23.31-99.91)\end{array}$ & $\begin{array}{c}74.33 \pm 31.71 \\
92.12(51.14-100.00)\end{array}$ \\
\hline $\begin{array}{l}\text { Total number of hospital pro- } \\
\text { viding rehabilitation therapy }^{\mathrm{e}}\end{array}$ & $\begin{array}{l}2.58 \pm 0.90^{* *} \\
2(2-3)\end{array}$ & $\begin{array}{l}3.16 \pm 1.24^{* *} \\
3(2-4)\end{array}$ & $\begin{array}{l}3.67 \pm 1.43^{* *} \\
3(3-5)\end{array}$ & $\begin{array}{l}2.87 \pm 1.15 \\
2(2-3)\end{array}$ \\
\hline $\begin{array}{l}\text { Number of hospitals with } \\
\text { continuous rehabilitation } \\
\text { therapy }\end{array}$ & $\begin{array}{l}2.34 \pm 0.72^{* *} \\
2(2-2)\end{array}$ & $\begin{array}{l}2.68 \pm 0.98 \\
2(2-3)\end{array}$ & $\begin{array}{l}2.75 \pm 0.98 \\
2(2-3)\end{array}$ & $\begin{array}{l}2.48 \pm 0.85 \\
2(2-3)\end{array}$ \\
\hline
\end{tabular}

Values are presented as mean \pm standard deviation or median (interquartile range 25 th-75th percentile) or number (\%). LoS, length of hospital stay.

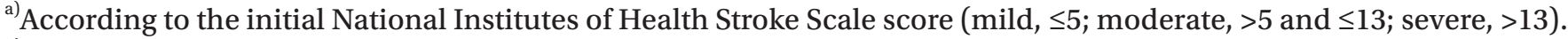

${ }^{b}$ Number of patients without rehabilitation therapy after acute care $=$ Total number of patients according to stroke severity - Number of patients with at least 1 rehabilitation therapy after acute care.

${ }^{c}$ Patients underwent rehabilitation therapy continuously following discharge from acute care center.

${ }^{d)}$ Proportion of LoS with continuous rehabilitation therapy $=$ LoS with continuous rehabilitation therapy / Total LoS.

${ }^{\text {e) }}$ Total number of hospitals performing rehabilitation therapy = Number of hospitals performing continuous or intermittent rehabilitation.

${ }^{*} \mathrm{p}<0.05,{ }^{* *} \mathrm{p}<0.01$.

charged, suggesting that it is important to continue rehabilitation from the early stages of stroke onset.

In addition, when comparing the mRS at discharge after acute care and the 1-year follow-up mRS of patients from group A with those of patients in groups B and C combined (groups that did not undergo rehabilitation after acute care) in both moderate and severe groups, group A showed significantly higher scores. This result appears to contradict the need for continuous rehabilitation reflected in home discharge rate from the second hospital. However, the change in the 1-year follow-up $\mathrm{mRS}$ at discharge after acute care was greater in group A, albeit by a small margin. This difference is not conclusive enough for clinical practice, but it suggested the possibil- ity of functional improvement with continuous rehabilitation. Further evaluation of mRS scores with additional data highlighting the specific characteristics (frequency, intensity, time, type, etc.) of continuous rehabilitation should further elucidate this point.

This study has several limitations. First, the study failed to determine the specific period in which rehabilitation was initiated at the acute care center. However, it is safe to assume that acute rehabilitation occurred within 48-72 hours of stroke onset according to guidelines, as all the 12 participating university hospitals in this study have a Department of Rehabilitation Medicine. In addition, because we investigated whether rehabilitation occurred after acute care based on specific claims of rehabilitation 
treatment fee, we considered patients to have received rehabilitation throughout the hospital stay, even when the treatment fee was only claimed for 1 day, which may have overestimated the LoS with rehabilitation. However, as patients stabilized beyond the acute stage of stroke continue to undergo rehabilitation in Korea, the possibility of overestimation of the parameters does not appear to have a significant influence on the interpretation of our findings related to rehabilitation according to stroke severity.

Another study limitation is that it was unclear whether the rehabilitation therapies were systematic and goal-oriented or whether they were adequate due to lack of quality control measures. Furthermore, the home discharge rate may have been underestimated because cases of readmission were not included in the calculation.

Nevertheless, this is the first study that analyzed the recent status of rehabilitation services in accordance with the severity of stroke in Korea. We found that despite the need for continuous rehabilitation of patients diagnosed with moderate and severe stroke, several patients fail to undergo adequate levels of rehabilitation. Furthermore, the use of a large dataset increased the accuracy of our analysis of the actual parameters and nationwide status of the distribution of rehabilitation services in Korea. We expect our wide-ranging analysis involving the recent status of post-stroke rehabilitation to offer valuable insights in establishing strategies and setting directions for appropriate policy measures in the future.

In conclusion, this is the first study that analyzed the status of rehabilitation system for stroke patients after acute care in Korea. In particular, our findings revealed that intermittent rehabilitation occurred more often than continuous intervention in many patients after acute care. However, continuous rehabilitation after acute care positively affects home discharge rate in the moderate and severe groups. This study provides evidence supporting the need for improving healthcare system to promote adequate rehabilitation services in the future.

\section{CONFLICT OF INTEREST}

No potential conflict of interest relevant to this article was reported.

\section{ACKNOWLEDGMENTS}

This study was supported by a 2012 grant from the Korean Academy of Medical Sciences.

\section{REFERENCES}

1. Langhorne P, Sandercock P, Prasad K. Evidence-based practice for stroke. Lancet Neurol 2009;8:308-9.

2. Stroke Unit Trialists' Collaboration. Organised inpatient (stroke unit) care for stroke. Cochrane Database Syst Rev 2013;9:CD000197.

3. Albert SJ, Kesselring J. Neurorehabilitation of stroke. J Neurol 2012;259:817-32.

4. Ottenbacher KJ, Jannell S. The results of clinical trials in stroke rehabilitation research. Arch Neurol 1993;50: 37-44.

5. Cifu DX, Stewart DG. Factors affecting functional outcome after stroke: a critical review of rehabilitation interventions. Arch Phys Med Rehabil 1999;80(5 Suppl 1):S35-9.

6. Stroke Unit Trialists' Collaboration. Organised inpatient (stroke unit) care for stroke. Cochrane Database Syst Rev 2007;4:CD000197.

7. Chang WH, Shin YI, Lee SG, Oh GJ, Lim YS, Kim YH. Characteristics of inpatient care and rehabilitation for acute first-ever stroke patients. Yonsei Med J 2015;56:262-70.

8. Kang JH, Bae HJ, Choi YA, Lee SH, Shin HI. Length of hospital stay after stroke: a Korean nationwide study. Ann Rehabil Med 2016;40:675-81.

9. Granger CV, Markello SJ, Graham JE, Deutsch A, Ottenbacher KJ. The uniform data system for medical rehabilitation: report of patients with stroke discharged from comprehensive medical programs in 2000-2007. Am J Phys Med Rehabil 2009;88:961-72.

10. Schlegel D, Kolb SJ, Luciano JM, Tovar JM, Cucchiara BL, Liebeskind DS, et al. Utility of the NIH Stroke Scale as a predictor of hospital disposition. Stroke 2003;34:134-7.

11. Bustamante A, Giralt D, Garcia-Berrocoso T, Rubiera M, Alvarez-Sabin J, Molina C, et al. The impact of post-stroke complications on in-hospital mortality depends on stroke severity. Eur Stroke J 2017;2;54-63.

12. Grube MM, Koennecke HC, Walter G, Meisel A, Sobesky J, Nolte CH, et al. Influence of acute compli- 
cations on outcome 3 months after ischemic stroke. PLoS One 2013;8:e75719.

13. Kang EK, Kim WS, Jeong SH, Shin HI, Han TR. Desire for rehabilitation services of stroke patients admitted in post-acute rehabilitation facilities. J Korean Acad Rehabil Med 2007;31:404-9.

14. Rah UW, Kim YH, Ohn SH, Chun MH, Kim MW, Yoo WK, et al. Clinical practice guideline for stroke rehabilitation in Korea 2012. Brain Neurorehabil 2014;7:S1-S75.

15. Langhorne P, Stott D, Knight A, Bernhardt J, Barer $D$, Watkins C. Very early rehabilitation or intensive telemetry after stroke: a pilot randomised trial. Cere- brovasc Dis 2010;29:352-60.

16. National Stroke Foundation. Clinical guideline for stroke management 2010. Melbourne: National Stroke Foundation; 2010.

17. Management of Stroke Rehabilitation Working Group. VA/DOD Clinical practice guideline for the management of stroke rehabilitation. J Rehabil Res Dev 2010;47:1-43.

18. Teasell R, Foley N, Salter K, Bhogal S, Jutai J, Speechley M. Evidence-Based Review of Stroke Rehabilitation: executive summary, 12th edition. Top Stroke Rehabil 2009;16:463-88. 